Article

\title{
A Sharable and Efficient Metadata Model for Heterogeneous Earth Observation Data Retrieval in Multi-Scale Flood Mapping
}

\section{Nengcheng Chen ${ }^{1,2, *}$, Lianjie Zhou ${ }^{1}$ and Zeqiang Chen ${ }^{1,2}$}

1 State Key Laboratory of Information Engineering in Surveying, Mapping, and Remote Sensing, Wuhan University, Luoyu Road 129, Wuhan 430079, China; E-Mails: zlj0808@whu.edu.cn (L.Z.); czq0119@whu.edu.cn (Z.C.)

2 Collaborative Innovation Center of Geospatial Technology, Wuhan University, Luoyu Road 129, Wuhan 430079, China

* Author to whom correspondence should be addressed; E-Mail: cnc@whu.edu.cn; Tel.: +86-27-6877-8586; Fax: +86-27-6877-8229.

Academic Editors: Guy J.-P. Schumann and Prasad S. Thenkabail

Received: 14 May 2015 / Accepted: 21 July 2015 / Published: 29 July 2015

\begin{abstract}
Remote sensing plays an important role in flood mapping and is helping advance flood monitoring and management. Multi-scale flood mapping is necessary for dividing floods into several stages for comprehensive management. However, existing data systems are typically heterogeneous owing to the use of different access protocols and archiving metadata models. In this paper, we proposed a sharable and efficient metadata model (APEOPM) for constructing an Earth observation (EO) data system to retrieve remote sensing data for flood mapping. The proposed model contains two sub-models, an access protocol model and an enhanced encoding model. The access protocol model helps unify heterogeneous access protocols and can achieve intelligent access via a semantic enhancement method. The enhanced encoding model helps unify a heterogeneous archiving metadata model. Wuhan city, one of the most important cities in the Yangtze River Economic Belt in China, is selected as a study area for testing the retrieval of heterogeneous EO data and flood mapping. The past torrential rain period from 25 March 2015 to 10 April 2015 is chosen as the temporal range in this study. To aid in comprehensive management, mapping is conducted at different spatial and temporal scales. In addition, the efficiency of data retrieval is analyzed, and validation between the flood maps and actual precipitation was conducted. The results show that the flood map coincided with the actual precipitation.
\end{abstract}


Keywords: multi-scale flood mapping; system of systems (SoS); sensor observation service (SOS); one-stop access; semantic enhancement; Wuhan city; hundreds of lakes

\section{Introduction}

Every year, floods cause numerous casualties [1]. In the last decade of the 20th century, floods directly or indirectly affected approximately 1.4 billion people, and approximately 100,000 people lost their lives [2]. Floods can be mapped and monitored using remotely-sensed data acquired by aircrafts and satellites. This method has incomparable advantages over ground observations [3,4].

Analysis of flood loss assessments: First, validating the results of flood hazards is difficult because ground-based observation are generally expensive and time consuming, and standard equipment is difficult to find [5]. The use of remote sensing images is a proven method for successfully monitoring changes in flood hazards in time and space [6]. Second, useful images for flood map are always insufficient on cloudy days, regardless of the range distance and solar/viewing geometry [6]. During rainy seasons, most optical remote sensing data are of limited use because of the high cloud rates during these seasons. Multi-scale flood maps can be analyzed to obtain useful information, including the inundation area, flood depth and the economic loss. Local governments can use these maps to estimate flood losses and make flood control decisions. From the above analysis, multi-scale flood map is meaningful for flood loss assessments for different temporal series, including before disasters, during disasters and after disasters, and at different spatial resolutions, including low, medium and high resolutions, for making a decision base for flood loss evaluation.

EO data systems are observation data archiving systems that store satellite observational data and metadata in archives. Because EO data systems are the foundation of EO data retrieval with the rapid development of EO technologies, various countries have established their own data systems. For example, the National Aeronautics and Space Administration (NASA) established the Earth Observing System Clearing House (ECHO) data system [7]; the National Oceanic and Atmospheric Administration (NOAA) established the Comprehensive Large Array-data Stewardship System (CLASS) data system [8], the United States Geological Survey (USGS) established the Landsat data system [9], the National Institute for Space Research in Brazil (INPE) established the China-Brazil Earth Resources Satellite (CBERS) data system [10], and the Chinese Academy of Sciences established the Academy of Opto-Electronics (AOE) data system. The access protocols of different data systems are different. For example, NASA ECHO provides the Web Services Definition Language (WSDL) file for users; NOAA CLASS provides users with the NOAA Enterprise Archive Access Tool (NEAAT) program; and USGS Landsat provides users with a specific network address. In addition to the different data system access protocols, the metadata models used for the archiving products are different. An analysis of EO data systems is shown in Table 1 . Various access protocols and metadata models of heterogeneous data systems make data searches difficult for users. 
Table 1. Analysis of typical EO data systems. ECHO, Earth Observing System Clearing House;

WSDL, Web Services Definition Language; NEAAT, Web Services Definition Language.

\begin{tabular}{|c|c|c|c|c|}
\hline Data System & NASA ECHO & NOAA CLASS & USGS Landsat & INPE CBERS \\
\hline $\begin{array}{l}\text { Name of EO } \\
\text { data system }\end{array}$ & $\begin{array}{l}\text { NASA Earth Observing } \\
\text { System Clearing House }\end{array}$ & $\begin{array}{c}\text { NOAA Comprehensive } \\
\text { Large Array-data } \\
\text { Stewardship System }\end{array}$ & USGS Landsat data system & $\begin{array}{l}\text { INPE China-Brazil } \\
\text { Earth Resources } \\
\text { Satellite data system }\end{array}$ \\
\hline Producer & NASA (America) & NOAA (America) & USGS (America) & INPE (China) \\
\hline $\begin{array}{l}\text { Access } \\
\text { protocol }\end{array}$ & ECHO WSDL & NEAAT API & Http web method & Http web method \\
\hline $\begin{array}{l}\text { Metadata } \\
\text { model }\end{array}$ & Granule/collection & Inventory/Catalog & $\begin{array}{c}\text { Federal Geographic Data } \\
\text { Committee (FGDC) Content } \\
\text { Standard for Digital } \\
\text { Geospatial Metadata }\end{array}$ & $\begin{array}{c}\text { FGDC Content } \\
\text { Standard for Digital } \\
\text { Geospatial Metadata }\end{array}$ \\
\hline $\begin{array}{c}\text { Response } \\
\text { dataset }\end{array}$ & GranuleURMetadata & InventoryDataset & FGDC Metadata & FGDC Metadata \\
\hline $\begin{array}{l}\text { Particular } \\
\text { features }\end{array}$ & Open & Open & None & None \\
\hline
\end{tabular}

Constructing an SoS [11,12] can help users obtain required information effectively. DeLaurentis stated that SoSs consist of multiple, heterogeneous, distributed and occasionally independent operating systems embedded in networks at multiple levels that evolve over time. In addition, SoSs are evolutionary, geographically distributed and integrated in a federated form. These systems are dynamic and composed of other independently-managed systems [13-15]. Building an SoS can save time and energy, because it can be used to access data systems within a specific application scene. The Water Observation and Information System is an open source software tool for monitoring, assessing and inventorying water resources in a cost-effective manner using remote sensing data [16].

A typical EO data SoS is constituted from different data systems. A typical EO data SoS contains the Global Earth Observation System of Systems (GEOSS) [17], the Copernicus Programme [18], the Committee on Earth Observation Satellites Working Group on Information Systems and Services Integrated Catalogue (CWIC) [19] and the Chinese geospatial data cloud data system (CGDC) [20]. The GEOSS includes an archived EO resource for metadata harvesting and analysis and EO resource discovery and presentation by combining self-nomination and automatic harvest approaches. Typical data systems contain NASA ECHO, NOAA CLASS, USGS Landsat and other EO data systems. The Europe Copernicus Programme integrates the Sentinel-1 and Sentinel-2 data systems. CWIC integrates the NASA ECHO, NOAA CLASS, USGS Landsat and INPE CBERS data systems. The CGCD data system integrates the Moderate-Resolution Imaging Spectroradiometer (MODIS), USGS Landsat and NASA Digital Elevation Model data systems.

The Group on Earth Observations resulted in the establishment of the GEOSS. Furthermore, SoSs aim to proactively link existing and planned observing systems around the world. This system is intended to support the development of new systems that will fill current gaps and provide an Internet access point through a portal for users seeking data, imagery and analytical software packages for any region around the world. The initial construction of GEOSS is complete. By 2015, GEOSS is expected to achieve sustained operation, continuity and interoperability for existing and new systems and to provide essential 
environmental observations and information. This cross-referencing approach avoids unnecessary duplications, encourages synergy between systems and ensures substantial economic, societal and environmental benefits.

The CWIC is the EO data system established by the Center for Spatially Integrated Social Science lab of George Mason University and is one of the contributions to the Committee on Earth Observation Satellites, which helps users identify and access satellite data of interest. The CWIC is designed using a mediator-wrapper architecture, which makes it easy to add new data partners. The CWIC integrates the NASA ECHO data system, the NOAA CLASS data system and the USGS Landsat data system. In the next stage, the system will integrate the Chinese AOE data system. The CWIC project has three pillars: a mediator-wrapper component, data partners and a Catalog Service for the Web (CSW) component. The development of a CWIC is based on the conversion of data system access protocols. The access protocol of CWIC is CSW, which has unified access protocols for different data systems.

The CGDC data system integrates MODIS, Advanced Very High Resolution Radiometer (AVHRR), Landsat ETM+ and DEM data access interfaces, which were developed and are maintained by the Chinese Academy of Sciences. These interfaces are easy to access and provide a convenient method for downloading data. The CGDC provides a snapshot of the searched data by resolving the metadata of the requested data product.

An EO data SoS is a successful integration of a typical EO data system. However, EO data systems of systems have several problems. First, these systems lack multi-scale spatial scale and temporal scale EO data for obtaining evolving flood maps. Disasters are divided into four phases, including mitigation, preparedness, response and recovery, according to the definition of the United Nations International Strategy for Disaster Risk [21]. The four phases of disasters in this paper are defined as diagnosis phase, preparedness phase, response phase and recovery phase, so flood mapping should be divided into several phases based on the four phases according to definition. Flood mapping during different periods requires data at different spatial and temporal scales. Second, the data system access protocol and archiving metadata model differ, making it more difficult to access heterogeneous EO data systems in one stop. The mentioned EO SoSs lack a unified and effective model.

Few existing models can help solve these problems. Overall, the goal of the proposed method is to provide a sharable and efficient metadata model that can build an SoS for accessing a heterogeneous EO data system. The model should be standard, extendible, explicit and comprehensive [22]. The entire model is named the access protocol and enhanced EO metadata profile model (APEOPM) and the EO metadata profile of observations and measurements is called EOP.

This study proposes a model in Section 2 that helps shelter the differences between the access protocols of the different EO data systems and different archiving metadata models to achieve multi-scale flood mapping. The two following objectives are considered: (1) the model to build SoS should unify the data system access protocol and the metadata model of heterogeneous EO data system; and (2) the model should be designed to support data retrieval for multi-scale flood mapping. The model can effectively integrate the access protocols and metadata models of heterogeneous data systems. The system developed based on the model can be used to achieve intelligent and efficient access of EO data systems. Section 2 describes the proposed methodology and implementation, including the access protocol model and the enhanced encoding model. Multi-scale flood mapping based on the proposed 
methodology and regarding Wuhan city is presented in Section 3. In addition, the analyses and discussion are presented, and the conclusions of the study and potential future directions are discussed.

\section{Methodology}

One unified model cannot account for the differences between access protocols and archiving metadata models. Thus, the proposed model is composed of two sub-models. Because the model should support the newly-added EO data system when possible, the entire model should be open and sharable. How to implement this characteristic is described at the end of the section. In addition, the entire model can be granted semantic relevance to improve the performance when accessing heterogeneous EO data systems.

As shown in Figure 1, from bottom to top, a heterogeneous EO data system as shown in the figure can be described by the proposed meta-model, which includes the access protocol model and the enhanced EOP, which is derived from the EOP and formalizes the specified EO product metadata [23]. The access protocol model supports unifying heterogeneous EO data system access protocols (i.e., the application can access a heterogeneous EO data system via an access protocol model, rather than a specified model of the heterogeneous EO data system). Thus, the access protocol model can help mask differences in the access protocols of heterogeneous EO data systems. Enhanced EOP supports the unification of heterogeneous EO data system archiving metadata models. Specifically, the end application, such as flood hazard mapping, can use archiving metadata through the enhanced EOP metadata model, rather than through the specified archiving metadata model, which can help reduce the apparent effects of the differences in the heterogeneous EO data system archiving metadata model. Sections 2.1 and 2.2 introduce the APEOPM, and Section 2.3 introduces the implementation and use of the APEOPM model. First of all, as there are some parts in the model and acronyms that are difficult to understand, Table 2 explains the parts in the model and the acronyms in Sections 2.1-2.3.

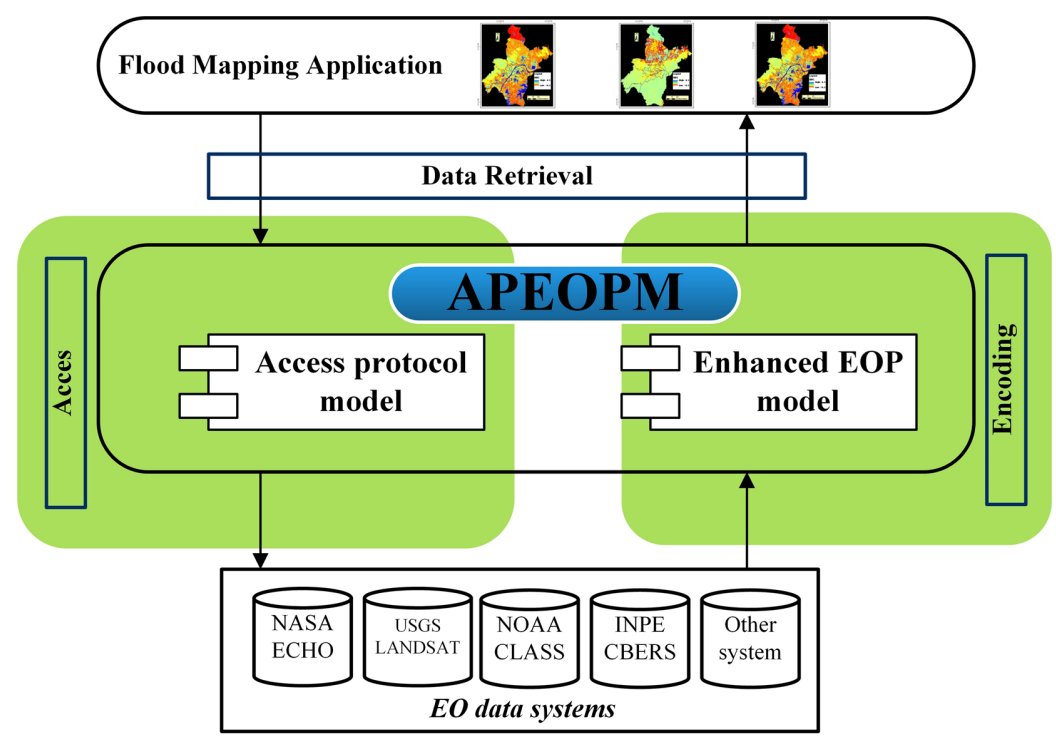

Figure 1. Architecture of the proposed access protocol and enhanced EO metadata profile model (APEOPM). In the whole figure, the green boxes stand for the individual parts of the model: the left green box is the access protocol model as shown in Section 2.1; the right green box stands for the enhanced EOP model, as shown in Section 2.2. 
Table 2. The acronyms or model parts and explanations.

\begin{tabular}{|c|c|}
\hline Parts in the Model & Explanations or Meaning \\
\hline AccessProtocol & The access protocol of heterogeneous EO data system \\
\hline Availability & $\begin{array}{l}\text { The necessary parameters while accessing EO data system, } \\
\text { such as the username and password }\end{array}$ \\
\hline productHierarchy & The product levels' classification system \\
\hline ProductTypes & The type of product \\
\hline productRank & Which level the product belongs to \\
\hline productRankName & The level name of the product \\
\hline productTag & The tag name of the product \\
\hline SOSSlot & The extension designed to be the access protocol for SOS \\
\hline EODataSystemFactory & Class of the EO data system abstract factory \\
\hline createEODataSystem & Class of the instantiated EO data system \\
\hline EODataSystem & Class of the EO data system \\
\hline NOAACLASSFactory & Object of the EO data system instantiated by NOAA CLASS \\
\hline NASAECHOFactory & Object of the EO data system instantiated by NASA ECHO \\
\hline
\end{tabular}

\subsection{Access Protocol Model for the Heterogeneous EO Data System}

The aim of this study is to provide a unified access protocol to couple or unify the access protocols of heterogeneous EO data systems, which can reduce the effects of the differences among the different access protocols of EO data systems. The model should be standard, general and have a clear structure. The SOS [24] offers pull-based access to sensor measurements and metadata, and the SOS provides standardized access to sensor observations and sensor metadata [25,26]. Based on these facts, we proposed an access protocol model that applies SOS to a coupled heterogeneous EO data system.

An access protocol meta-model is shown in Figure 2. The model carries semantic information through semantic enhancement. Henson et al. built a semantic SOS based on SOS implementation, added semantic enhancement for sensor data and realized high-level queries and sensor observations by adopting the observations and measurements (O\&M) encoding model [27-29].

The access protocol model takes advantage of semantic enhancement. In the access protocol model, AccessProtocol is the kernel attribute in the meta-model. In addition, Parameters can help users understand the EO data system, including the name, origin country and owner of the data system and the contact information. Furthermore, Availability helps users access the data system in the specified protocol. The username and password are given here. The access method, such as the order and FTP, WSDL or Http modes, are listed, and the access address is described in the model. In addition, productHierarchy covers the ProductTypes and productRank, and productTypes describes the product types that exist in the data system. Furthermore, productRank describes the product grades in the data system, and both productRankName and productTypes are semantically related to productTag. SOSSlot provides the unified EO data system access protocol and is more important than the SOSSlot for unifying the different access protocols of data systems with the access protocol of the SOS. The heterogeneous EO data system access protocols are converted to access the protocols of an SOS web service. 


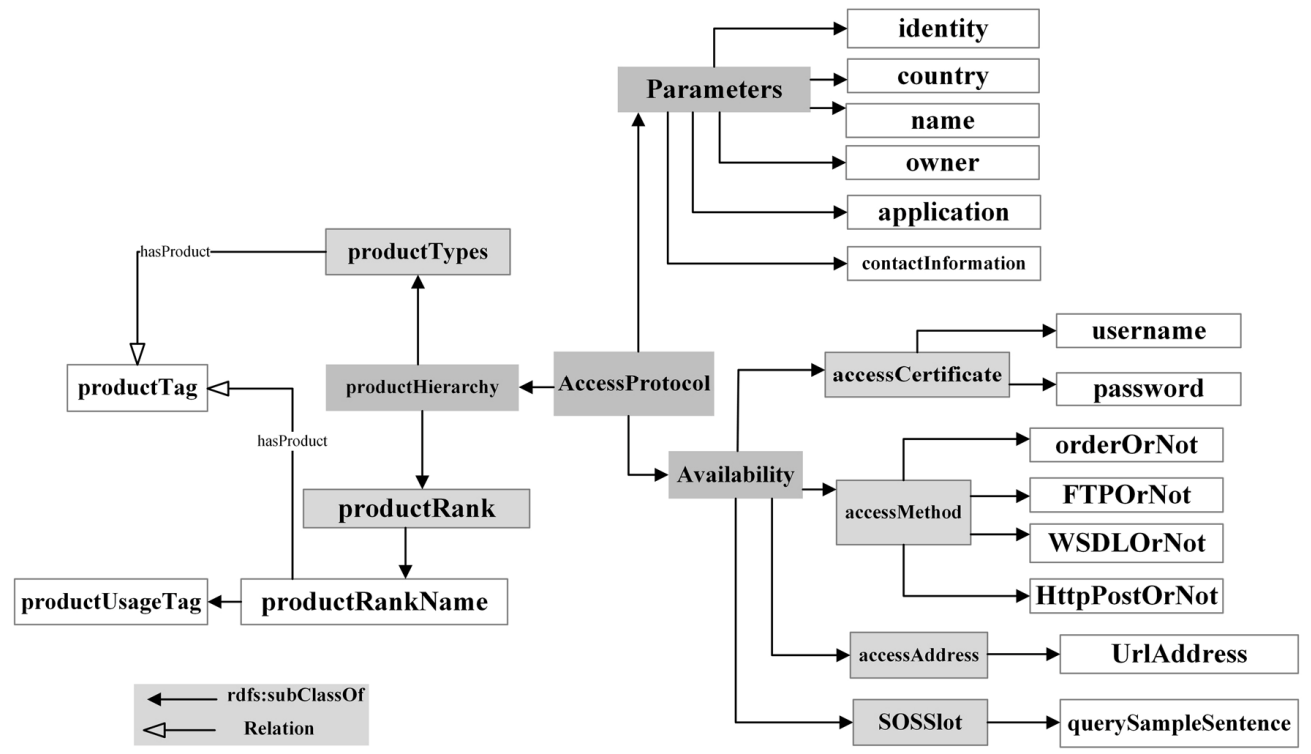

Figure 2. Access protocol model, containing the access protocol information, product information and the availability information.

The access protocol model is shown in Figure 2 and covers the attributes of the general EO data system, the availability and the productHierarchy attribute, which is vital for Earth data product searching. The metadata model functions as follows:

(1) The model helps the user or application search the EO data system access protocols more precisely when the data type and data hierarchy are rich in semantics. If a user searches the product name, such as "MODIS Level 3 ice and snow cover product", the semantic model will search the MOD33, MOD40, MOD42 and MOD43 product by resolving the EO data system access protocol instantiation file. Then, the single result searched for in a single data system will be assembled into a complete result and returned to the user or application [30].

(2) The model helps the user or application search the EO data system access protocol completely when the different data systems and data types are rich in semantics. Different data systems have different data products. The data stored in ECHO MODIS include different grades of MODIS data products, such as Level 0 to 4 data. The data stored in NOAA CLASS consist of different types of AVHRR data and other types of data. The data stored in USGS Landsat include Enhanced Thematic Mapper (ETM+) data, Thematic Mapper data, Multispectral Scanner data, elevation data, Landsat products (e.g., forest and tree data), specified MODIS data (e.g., 32-day composite product and 16-day vegetation index product), AVHRR data (e.g., global land cover product and continuous-field tree cover product), ETM+ mosaics products and TM mosaics products. The resolved data types in a specified data system allow the model to search the data system that contains the requested data product. Then, the single result searched in a single data system is assembled into a complete result and returned to the user or application.

How does the access protocol model formalized file work to access an EO data system? For example, the access protocol model instantiation file of a searched EO data system can be generated using the access protocol meta-model above, which describes the parameters of the data system, the product hierarchy and how to access the data system. After resolving the requested file sent by the user or 
application via the parser, the product type can be obtained. Furthermore, the Simple Protocol and Resource Description Framework Query Language (SPARQL) is generally considered a querying language for Resource Description Framework (RDF) files and is applied to obtain interesting information regarding existing RDF files with the help of semantic analyzing tools, such as Jena implementation [31]. During construction, a SPARQL sentence searches the data type above and the EO data system access protocol instantiation file. Thus, the data hierarchy will be resolved for data collection. For example, through a SPARQL query sentence, the data system containing the product name of "StandardLandDataProductLevel2" will be retrieved. By searching the data system according to the data type collection, the results will be obtained and returned to the user or application.

\subsection{Enhanced EOP Model for Abundant EO Metadata}

Presently, metadata specifications for geospatial information are mainly established by the International Organization for Standardization/Technical Committee (ISO/TC) 211, the Open GIS Consortium (OGC), FGDC and NASA, including NASA Global Change Master Directory, FGDC-Remote Sensing Extension, ISO 19115, ISO 19115-2, ISO 19130, OGC Catalog Service for the Web application profiles for EO products and the EOP encoding format [32-36], as listed in Table 3. China has developed the National Standard Guide Technical Document 24357-2009, spelled as GuoBiao/Zhi (GB/Z), to define geospatial metadata Extensible Markup Language formulations by the Chinese State Bureau of Surveying and Mapping in 2009 [37]. These standards define the metadata of a sensor, platform and observation data. Di et al. noted that the availability of metadata for the sensor web could be used to determine the correct resource at the correct time and location with the appropriate quality [38].

Table 3. Feature comparison of several EO encoding standards. OGC, Open GIS Consortium; CSW, Catalog Service for the Web.

\begin{tabular}{|c|c|c|c|c|c|}
\hline Features & ISO19115 & $\begin{array}{c}\text { Geographical Data } \\
\text { Description Directory }\end{array}$ & $\begin{array}{c}\text { GB/Z } \\
24357-2009\end{array}$ & $\begin{array}{l}\text { EOP Encoding } \\
\text { Model }\end{array}$ & $\begin{array}{c}\text { OGC CSW } \\
\text { Application Profile } \\
\text { for EO Products }\end{array}$ \\
\hline \multicolumn{6}{|l|}{ Main aspects } \\
\hline PlatformShortName & $\sqrt{ }$ & $\sqrt{ }$ & $\sqrt{ }$ & $\sqrt{ }$ & $\sqrt{ }$ \\
\hline PlatformType & $\sqrt{ }$ & $\sqrt{ }$ & $\sqrt{ }$ & $\sqrt{ }$ & $\sqrt{ }$ \\
\hline SensorShortName & $\sqrt{ }$ & $\mathrm{O}$ & $\mathrm{O}$ & $\sqrt{ }$ & $\sqrt{ }$ \\
\hline SensorResolution & $\sqrt{ }$ & $x$ & $\sqrt{ }$ & $\sqrt{ }$ & $\sqrt{ }$ \\
\hline temporalDomain & $\sqrt{ }$ & $\sqrt{ }$ & $\sqrt{ }$ & $\sqrt{ }$ & $\sqrt{ }$ \\
\hline spatialDomain & $\sqrt{ }$ & $\sqrt{ }$ & $\sqrt{ }$ & $\sqrt{ }$ & $\sqrt{ }$ \\
\hline FootPrint & $x$ & $x$ & $x$ & $\sqrt{ }$ & $\sqrt{ }$ \\
\hline Snapshot & $x$ & $x$ & $x$ & $\sqrt{ }$ & $\sqrt{ }$ \\
\hline DataSize & $\sqrt{ }$ & $\mathrm{O}$ & $\mathrm{O}$ & $\sqrt{ }$ & $\sqrt{ }$ \\
\hline DataFormat & $\sqrt{ }$ & $\mathrm{O}$ & $\mathrm{O}$ & $\sqrt{ }$ & $\sqrt{ }$ \\
\hline DataCenter & $\sqrt{ }$ & $\sqrt{ }$ & $\sqrt{ }$ & $\sqrt{ }$ & $\sqrt{ }$ \\
\hline DayNightFlag & $x$ & $x$ & $x$ & $x$ & $x$ \\
\hline DataSetId & $x$ & $x$ & $x$ & $x$ & $x$ \\
\hline Orderable & $\times$ & $x$ & $\times$ & $x$ & $x$ \\
\hline Focus & $\begin{array}{l}\text { Geographic } \\
\text { Metadata }\end{array}$ & Spatial data & $\begin{array}{l}\text { Spatial data } \\
\text { formulation }\end{array}$ & EO metadata & EO metadata \\
\hline Usage & Datasets & Datasets & Datasets & Datasets & Datasets \\
\hline Encoding schema & XML & N/A & XML & XML & XML \\
\hline
\end{tabular}


As shown in Figure 3, EO product metadata can be decomposed into a product tag, platform, product geoLocation, quality and metadata. Each segment contains its own sensor information. Particularly, various types of EO product information can be formalized using different data types, which are defined by the seven-tuple enhanced EOP model. The seven-tuple model is a concept from ontology in philosophy. Based on the components and metadata requirements, detailed metadata contents can be expressed as $\mathrm{MD}=\{$ PhenomenonTime, ObservedProperty, Platform, FootPrint, ObservationResult, SnapShot, Result-affiliated\}, which represent the seven aspects of the EO product information.

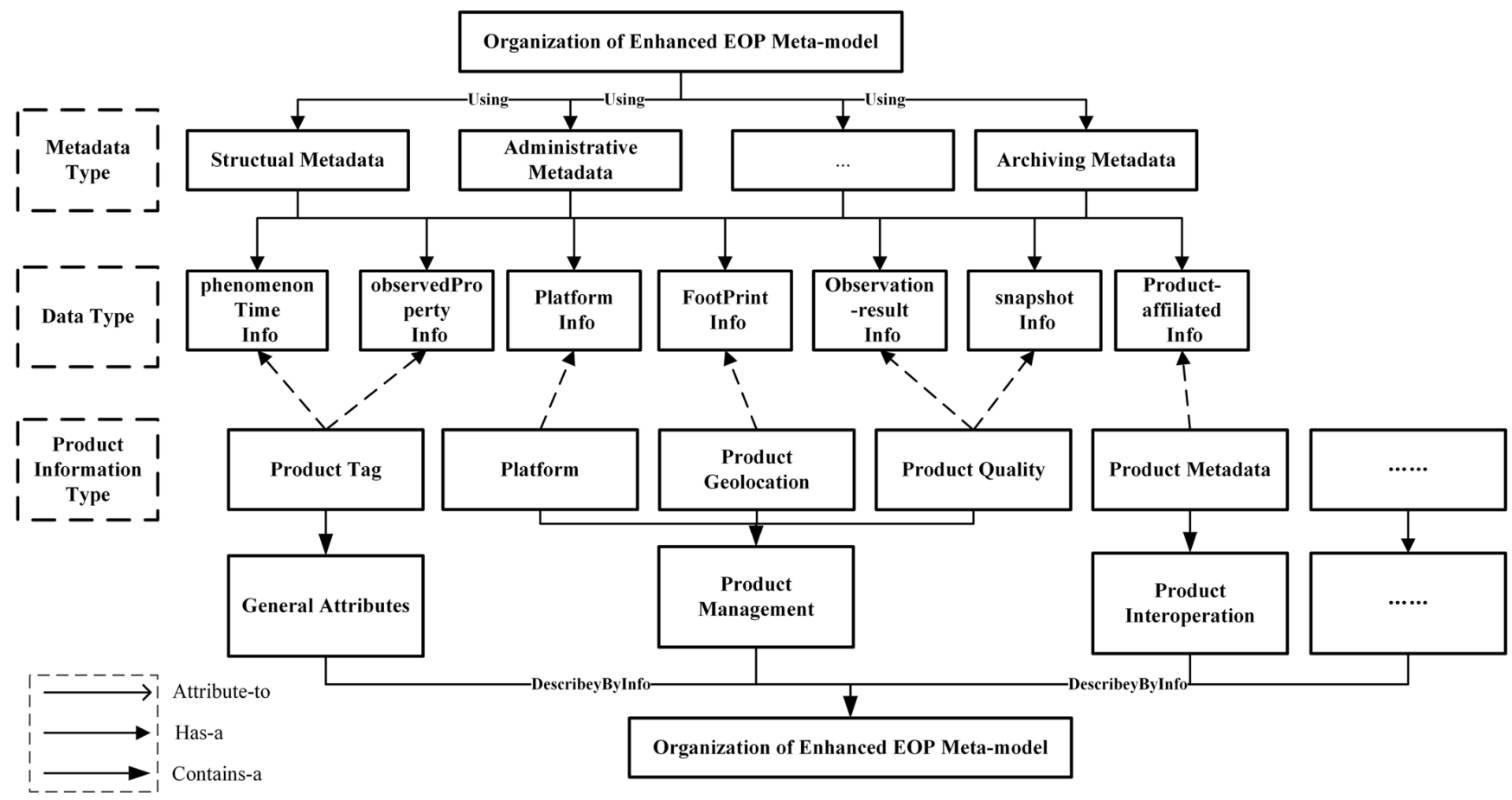

Figure 3. Enhanced EOP meta-model structure.

The product tag, platform, geoLocation product, product quality and product metadata components of a portion of an EO product are supported by the phenomenonTime and observedProperty information, platform information, footprint information, observation-result information, snapshot information and result-affiliated information, respectively. The basic components could be formalized by using detailed data types. The relationships between the node metadata and seven-tuples components are shown in Figure 3. According to the description structure of the seven-tuple node information, the common metadata features and their data types and constraint conditions are defined in the Unified Modeling Language (UML) diagram shown in Figure S1.

(1) PhenomenonTime information: This information includes the start and end times of observation, which provide temporal information for the product.

(2) ObservedProperty information: This information includes the observational properties obtained during the observation process.

(3) Platform information: Such information includes the name, the type of the platform and the name, type and resolution of the instrument carried on the platform.

(4) FootPrint information: This information includes the coordinates of the boundary points of the observation range and the coordinates of the center point of the observation range. FootPrint 
information is unique in EO products, which are important for describing the spatial range of EO products.

(5) ObservationResult information: This information includes a space referencing framework, file names and the coverage link address of the specified product.

(6) SnapShot information: This information includes the quick look image of the observation result, followed by the format description of the image. The quick look image can be helpful for identifying the correctness of the image and for previewing EO data.

(7) Result-affiliated information: This information includes the product type, the size of the data pool for a specified product, the name of the product archived at the data center, the data archiving time and the product processing level.

\subsection{Adapter for Heterogeneous EO Data Systems}

To implement the sharable model, this paper introduces a common design pattern in software development. Each EO data system has its own access portal and metadata model. NASA ECHO's access portal is the WSDL interface, and the metadata model is a granule and collection model. The NOAA CLASS access portal is NEAAT API, and the metadata model includes inventories and catalogues. An EO data system adapter can be dynamically instantiated and used to access different sources of the EO data system. The SOS service and its sensor data adapter will reside on the same server. In addition, SOS resources have an associated set of configuration files that specify the activities that the SOS supports, including the session information and the class name of its data resource adapter.

The SOS data adapter is designed and implemented using the abstract factory design pattern. The abstract factory design pattern is intended to "provide an interface for creating families of related or dependent objects without specifying their concrete classes" [39].

Figure 4 shows that the abstract factory class EODataSystemFactory provides interfaces for creating a number of data adapter instances (NASA ECHO data system and NOAA CLASS data system). This system can include several derived concrete versions of the database creator class, such as NASAECHOFactory or NOAACLASSFactory from Figure 4, with each version corresponding to a different implementation of createEODataSystem from Figure 4 that could create a corresponding object, such as NASA ECHO or NOAA CLASS. Each of these data adapters was derived from a simple abstract class, such as the EODataSystem from Figure 4, of which the client is aware. The client code would obtain an appropriate instantiation of the EODataSystem factory and use factory-related methods. The resulting objects would all be created from the same implementation and would share a common theme. The client would only need to know how to handle the abstract EODataSystem class and would not need to handle the specific version that it obtained from the concrete factory.

The entire SOS is implemented using Java language. If users want to add a new EO data system, they only need to implement the proposed factory and interface to write the EODataSystem implementation. Thus, it is very easy for users to implement the SOS. For example, if the objective is to extend a data adapter to register a sensor or insert observations and obtain observations from the EODataSystemX, then the EODataSystemXFactory and EODataSystemX classes must be written. The concrete EODataSystemXFactory class is used to create an instance of EODataSystemX, and the EODataSystemX class is used to implement the proposed nine common interfaces of the SOS database 
abstract class. Because the specified access protocol of APEOPM is exposed to SOS, so the implementation of the conversion between the heterogeneous EO data system and the interface of the SOS web service is essential as shown in Table S1.

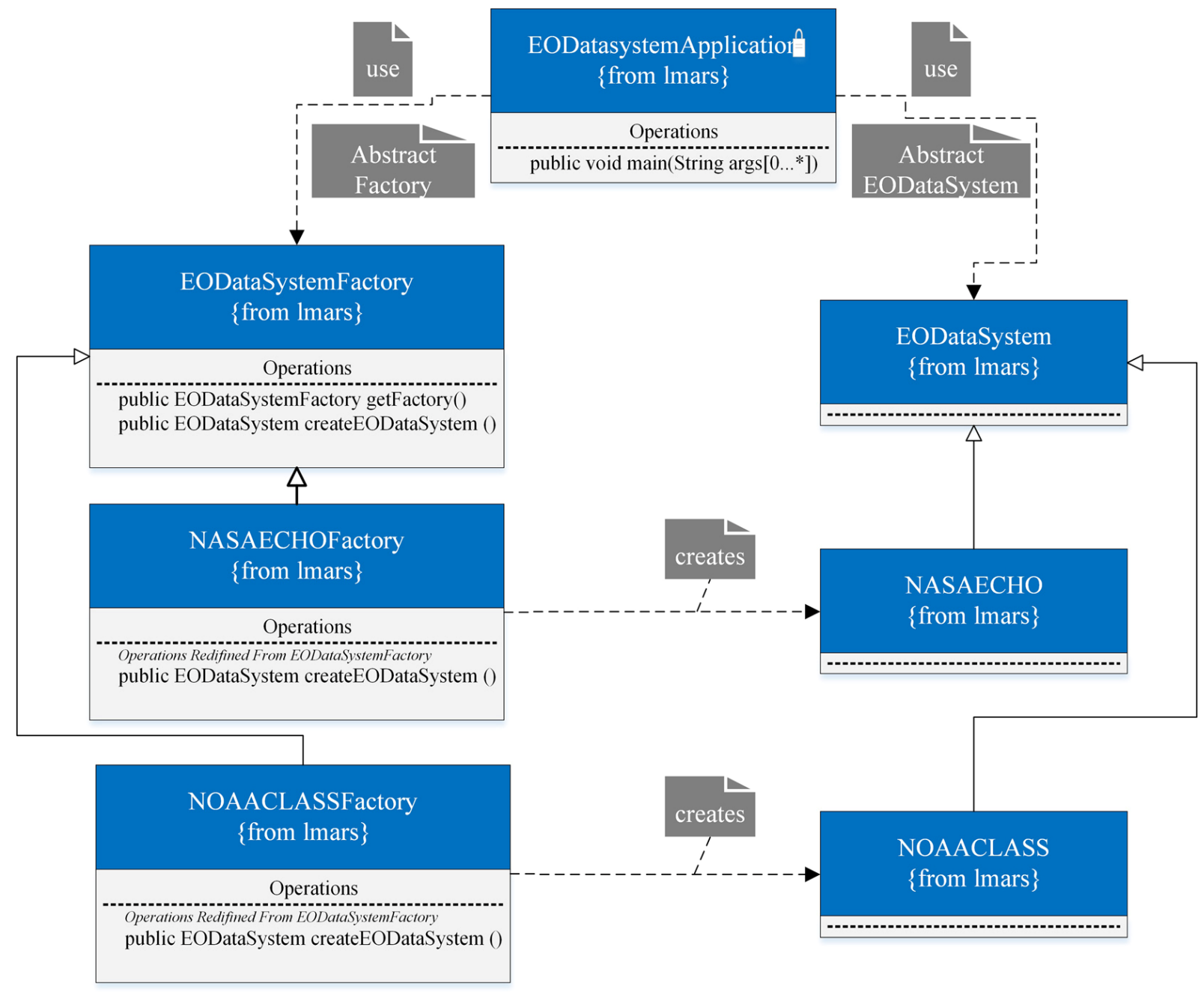

Figure 4. Abstract factory implementation of an EO data system adaptor.

\section{Experiment}

\subsection{Study Area}

In this experiment, Wuhan city, with a booming economy and flourishing culture, was studied. As one of the most important cities in the Yangtze River Economic Belt in China, Wuhan plays an important role in education, cultural diplomacy and economic development in Hubei. Because of the economic position of Wuhan city, it is important to study Wuhan city. City waterlogging is a comprehensive phenomenon, especially in cities with multiple lakes, such as Wuhan city, which is called the "hundreds of lakes city". Because the drainage system in the city needs to be improved, Wuhan suffers a lot during torrential rainfall. Thus, the period considered in this study extended from 26 March 2015 to 9 April 2015 , and the experimental spatial extent includes the case study area from $113.33^{\circ} \mathrm{E}$ to $116.05^{\circ} \mathrm{E}$ and the latitude range from $29.01^{\circ} \mathrm{N}$ to $32.73^{\circ} \mathrm{N}$ (see from Figure 5). Wuhan city contains 13 districts, as shown in Figure 5. 


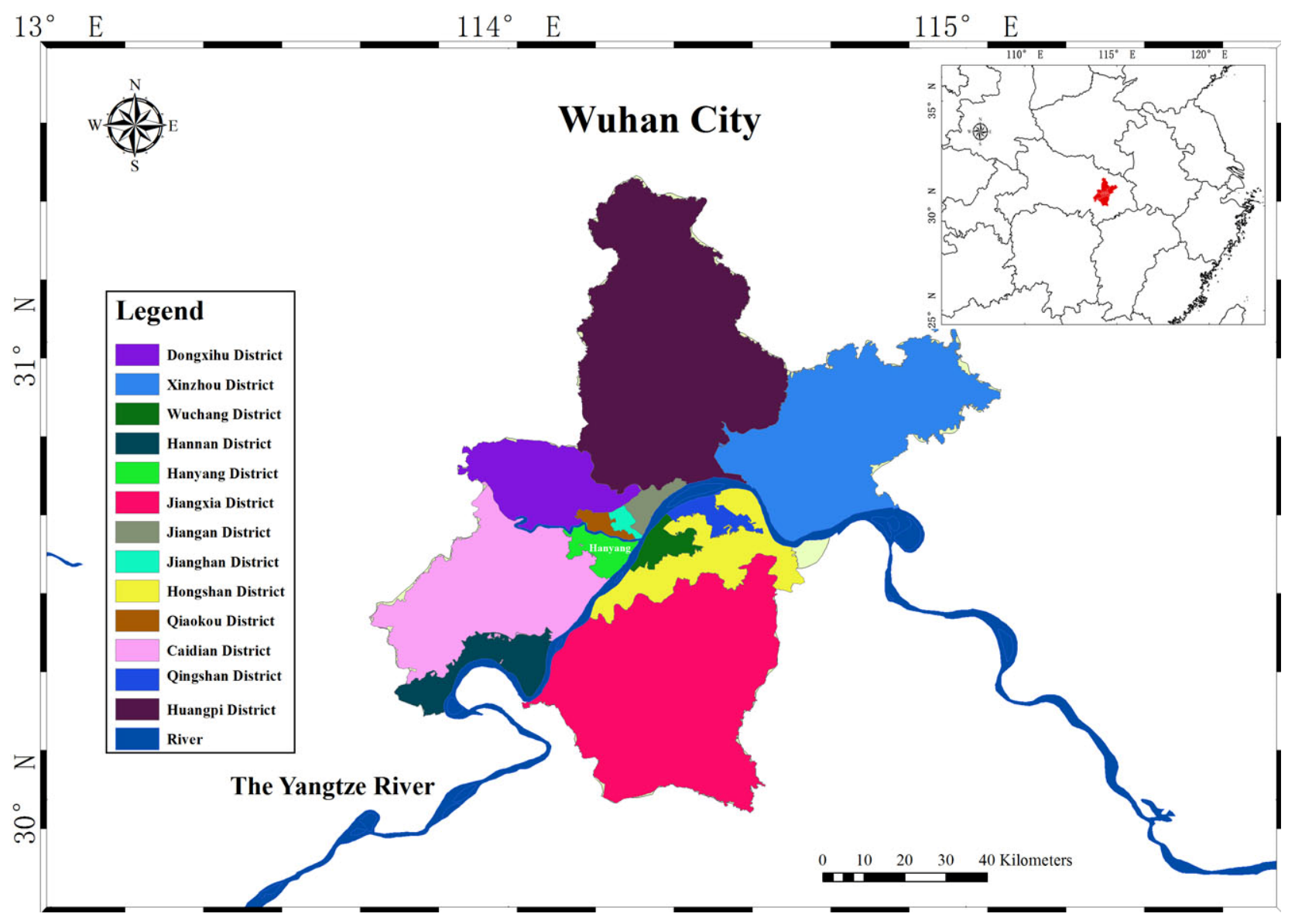

Figure 5. Location of Wuhan city, the city with hundreds of lakes.

\subsection{Data Retrieval}

To achieve multi-scale flood mapping based on the flooding area or waterlogging area, different spatial scales and temporal dimensions should be used when obtaining remote sensing data. The prototype was developed based on the methodology and implementation design described in Section 2. The SosSystem prototype [40] was deployed to test for rationality by allowing the research team to provide the following functions: integration of different EO data systems and encoding the metadata in enhanced EOP encoding format. By setting up the targeted spatial and temporal range, the resulting data can be obtained in the metadata encoded in the enhanced EOP encoding format after waiting several seconds.

Flood mapping is a comprehensive task for different temporal and spatial dimensions. Thus, low-resolution, mid-resolution and high-resolution satellite observation data are considered. Moreover, the data should also be retrieved before, during and after torrential rain days. Thus, low-resolution data, such as AVHRR or MODIS data, are selected, and mid-resolution data, such as Landsat 8 OLI data, are selected. The 16-m resolution GaoFen-1 (GF-1) data are selected as the highest spatial resolution in the experiment.

The enhanced EOP encoding file describes most of the metadata. The observation time attribute includes the beginning and end times, and the observedProperty attribute refers to the sensor platform used in the observation process. The observation result attribute contains the data product URL address and the snapshot image of the network address. In the metadata attribute, the data size, data format and archiving data center are recorded. The footprint information contains the boundary and the center of the observation coverage. The boundary of the observation coverage refers to a series of break point 
coordinates. The platform contains the platform information and the sensor information. In addition, the platform information refers to the platform name and the carried sensor information. The sensor information contains the resolution and the short name of the sensor. Overall, the enhanced EOP model supports a precise and formalized expression of EO products.

\subsection{Flood Mapping}

To obtain knowledge of flooding or waterlogging situations and to qualitatively assess the disaster range, this experiment employed a simple computing model named Normalized Difference Water Index (NDWI), as suggested by Gao and McFeeters [41,42]. The NDWI was developed to depict the open water present in remotely-sensed images by using near IR and visible green light to enhance water in remote sensing images. Water features can result in water values in the NDWI. The NDWI is widely applied for flood mapping, vegetation water content estimations and flood disaster assessments [43-46]. According to Gao [41], the NDWI was calculated as follows:

$$
\begin{gathered}
N D W I=\frac{p(\text { Green })-p(\text { Nir })}{p(\text { Green })+p(\text { Nir })} \\
N D W I=\frac{p(\text { NIR })-p(\text { MIR })}{p(\text { NIR })+p(\text { MIR })}
\end{gathered}
$$

However, the first formula is utilized in the study. Figures 6-9 show the AVHRR, Terra/MODIS, Landsat 8 OLI and GF-1 waterlogging NDWI distributions in Wuhan city, respectively. When using the ENVI software, data correction and NDWI computation are convenient.

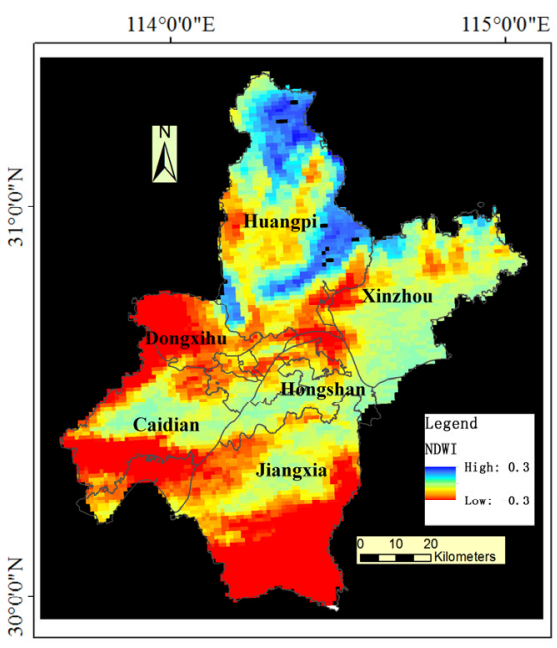

(a)

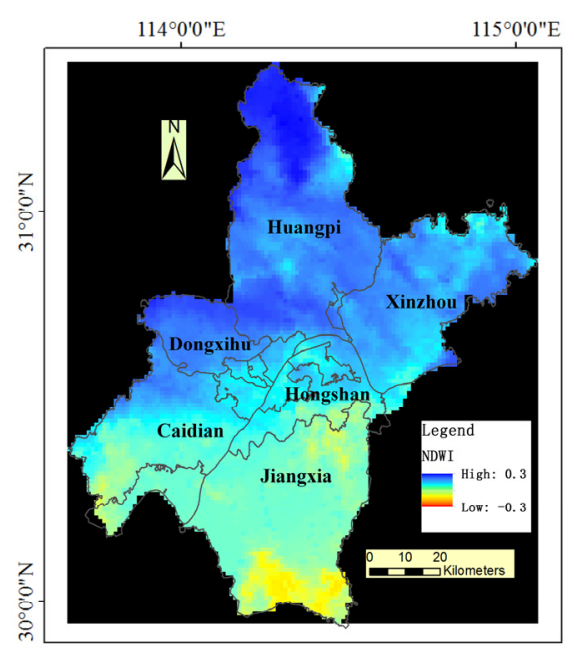

(b)

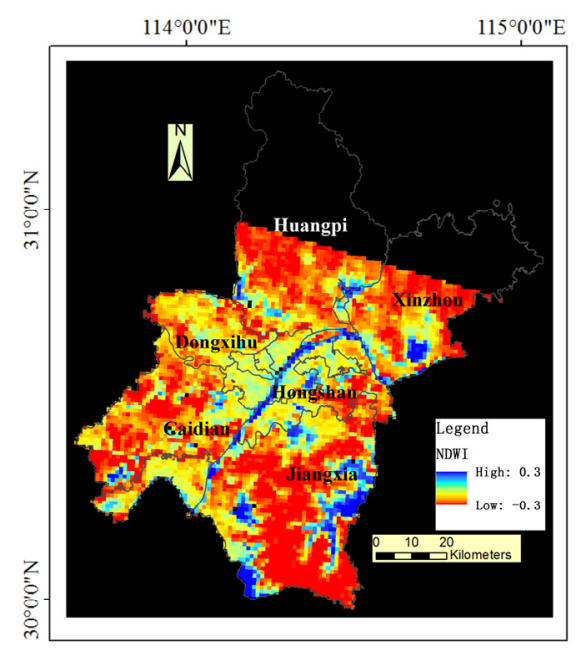

(c)

Figure 6. AVHRR waterlog NDWI distributions in Wuhan city during periods of torrential rainfall: 27 March 2015 (a), 1 April 2015 (b) and 8 April 2015 (c).

As flooding ended in Wuhan city, we referred to the conditions as waterlogged instead of flooded in Figures 6-9. Multi-scale waterlog mapping has been performed by applying NDWI models. However, the cloud cover can affect the optical sensing imagery in flood mapping heavily, especially on rainy days. In Figures 6-9, figures labeled (a) cover the phase before flood disaster, (b) cover the diagnosis phase in flood disasters and (c) cover the recovery phase in flood disasters. 


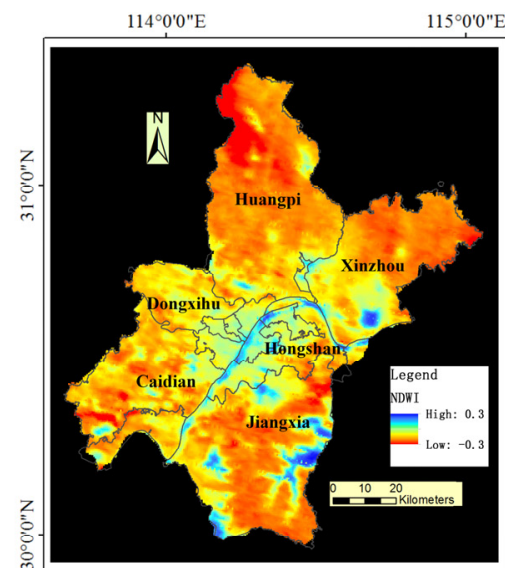

(a)

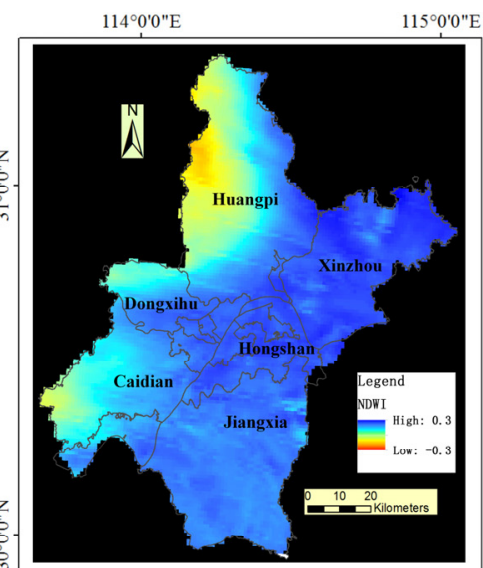

(b)

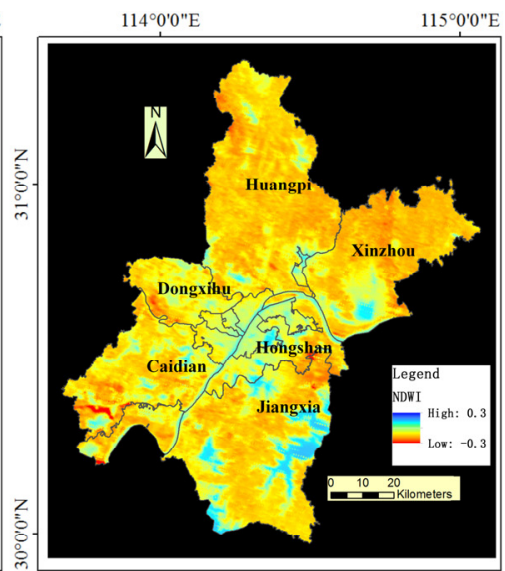

(c)

Figure 7. Terra/MODIS waterlog NDWI distributions in Wuhan city during periods of torrential rainfall: 30 March 2015 (a), 2 April 2015 (b) and 7 April 2015 (c). Normalized Difference Water Index.

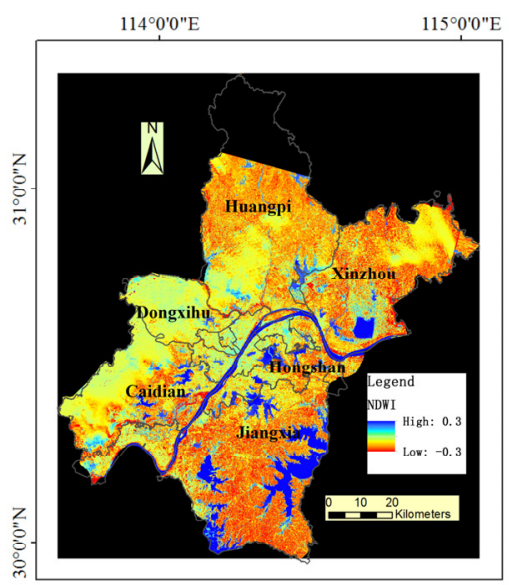

(a)

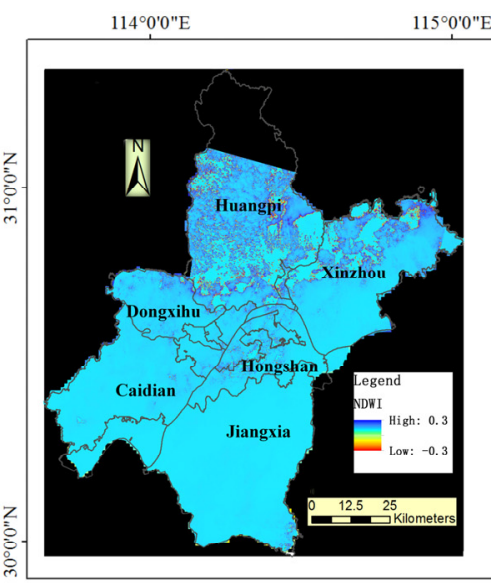

(b)

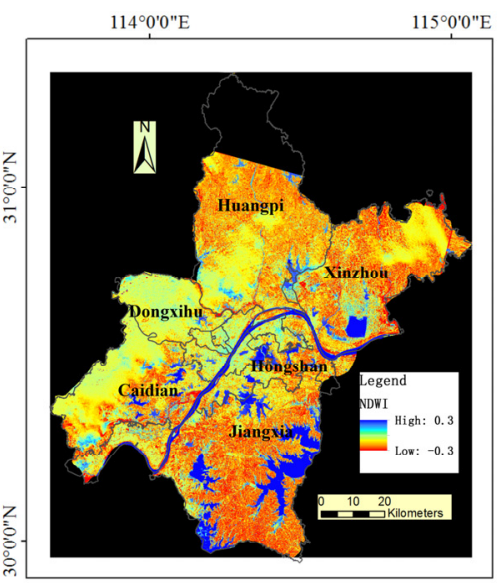

(c)

Figure 8. Landsat 8 OLI waterlog NDWI distributions in Wuhan city during periods of torrential rainfall: 27 March 2015 (a), 2 April 2015 (b) and 07 April 2015 (c).

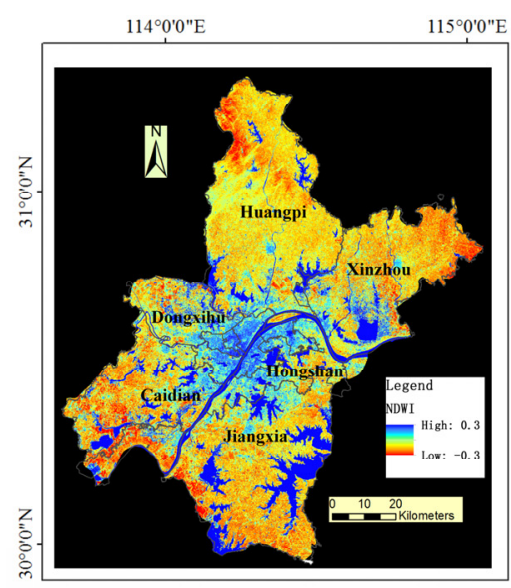

(a)

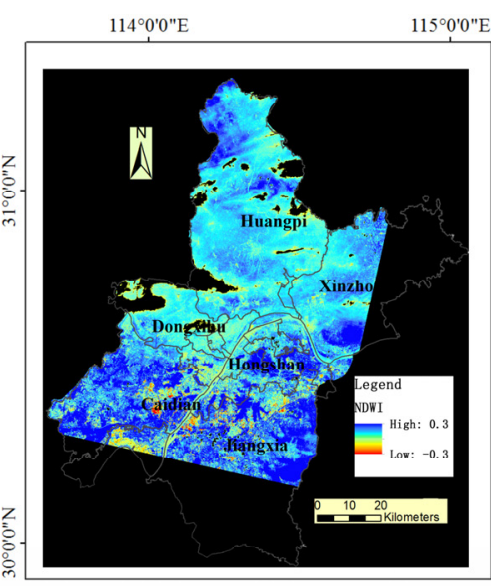

(b)

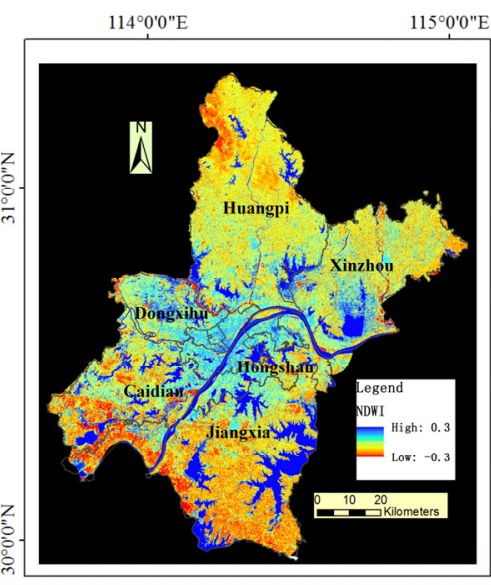

(c)

Figure 9. GF-1 waterlog NDWI distributions in Wuhan city during periods of torrential rainfall: 31 March 2015 (a), 3 April 2015 (b) and 10 April 2015 (c). 


\subsection{Precision Analysis}

A comparison of APEOPM, the CGDC and GEOSS is presented below.

Precision measurements are used to determine the quality of retrieved documents [45]. Precision can be used to evaluate the discovery of data products. Over different temporal and spatial ranges, the query test was repeated approximately 50 times, and the obtained data were analyzed. If the observation time of the queried data occurs within the requested time range and the spatial domain is located or inserted within the requested spatial range, the queried data can be viewed as correct; otherwise, the data are viewed as false.

Precision reflects the share of real correspondences between all of the identified correspondences.

$$
\text { Precision }=\frac{T}{P}
$$

Here, $T$ represents the true matches and the number of desired data records, and $P$ denotes the total number of searched data records.

The precisions of the three methods for the MODIS and other EO data are described in Figure 10. Figure 10a shows that the APEOPM method yields the best precision for MODIS Level 2 Sea data (91\%), MODIS Level 3 Atmosphere data (86\%) and MODIS Level 4 Land data (89\%). The mean precisions of APEOPM, CGDC and GEOSS reach up to $88 \%, 86 \%$ and $87 \%$, respectively. The precisions of the three methods for accessing AVHRR data and Landsat 7 ETM+ are described in Figure 10. Figure 10b shows that the APEOPM method yielded good precision for the AVHRR data (86\%). The mean precisions of the APEOPM, CGDC and GEOSS models for the AVHRR data reached approximately $88 \%, 56 \%$ and $85 \%$, respectively. In addition, the mean precisions of the APEOPM, CGDC and GEOSS models for the Landsat 7 ETM+ data were approximately $88 \%, 85 \%$ and $83 \%$, respectively. However, to test the precision for different spatial ranges and temporal ranges, more experiments were conducted. Figure 10c shows that for Hubei province, the APEOPM method yields the best precision for MODIS Level 2 Sea data (96\%), MODIS Level 3 Atmosphere data (92\%) and MODIS Level 4 Land data (91\%). The mean precisions of APEOPM, CGDC and GEOSS reach up to 94\%, 75\% and 79\%, respectively. From 01 May 2015 to 05 May 2015, the APEOPM method yields the best precision for MODIS Level 2 Sea data (100\%), MODIS Level 3 Atmosphere data (85\%) and MODIS Level 4 Land data (100\%).

From Figure 10a-d, the precision of data retrieval for MODIS and other EO data are analyzed. The mean precision of APEOPM is preferable to CGDC and GEOSS's. The explanation is given as follows: Having instantiated different EO data system' access protocols based on the access protocol model proposed in Section 2.1, the ontology instantiation files were queried to get the specified EO data system collection storing the queried EO data. Then, EO data were obtained by querying the EO data system collection. Consequently, more of the desired EO data were queried via APEOPM than other methods, such as GEOSS or CGDC. Therefore, the precision is promoted correspondingly. In conclusion, the precisions are promoted by constructing the semantic association in the access protocol model to yield the desired EO data. Owing to semantic enhancement, the model can yield better precision than other methods. 


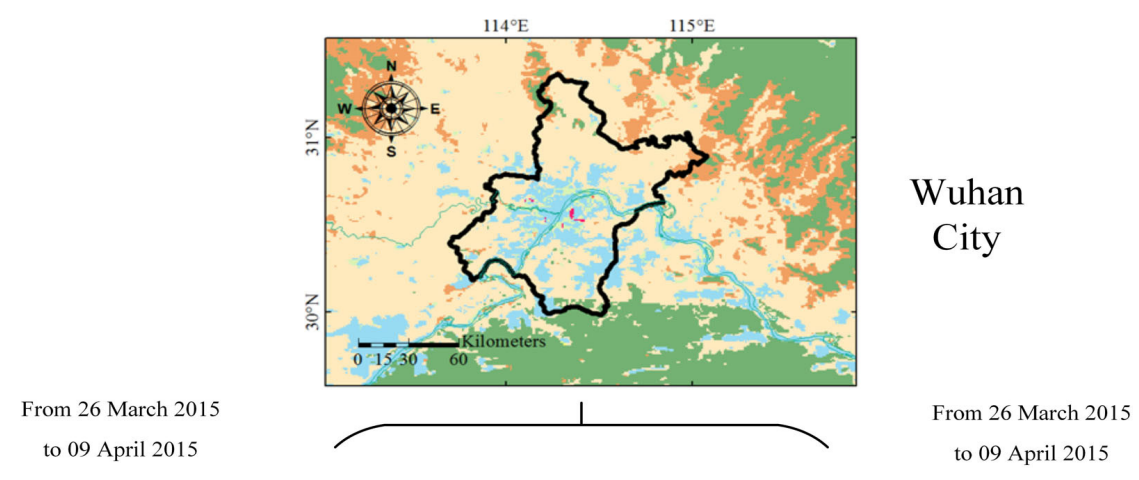

(a)

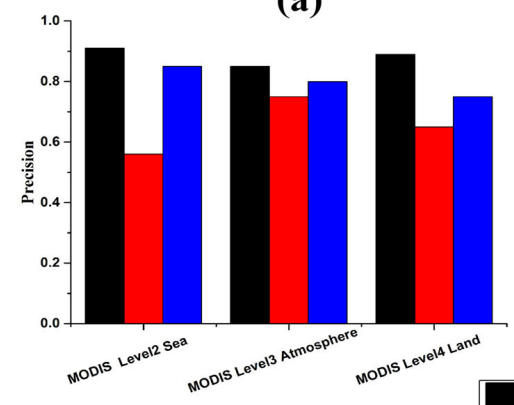

(b)

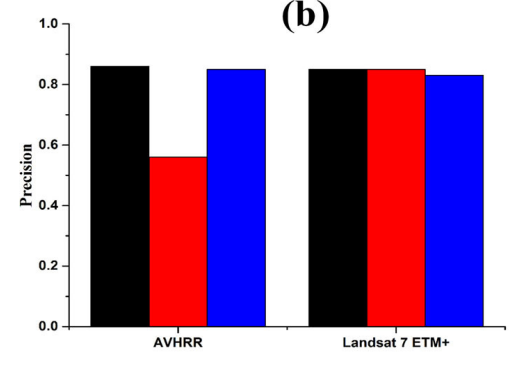

APEOPM CGDC

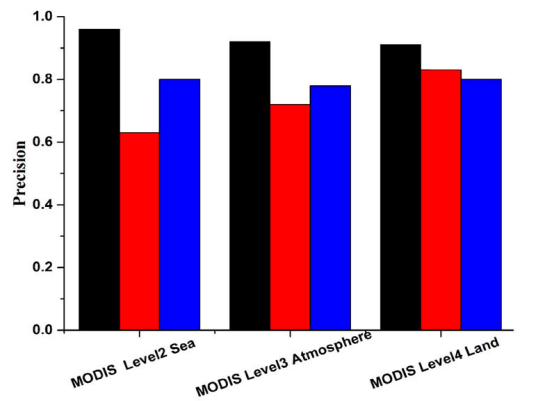

(c)

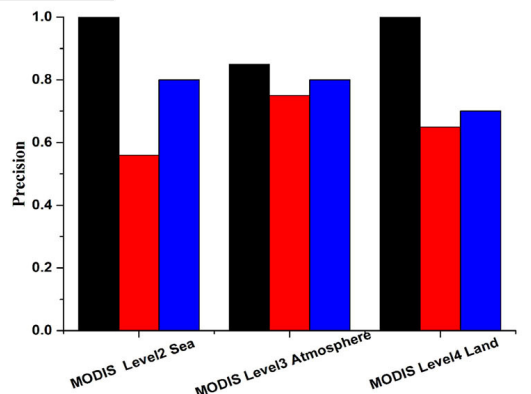

(d)

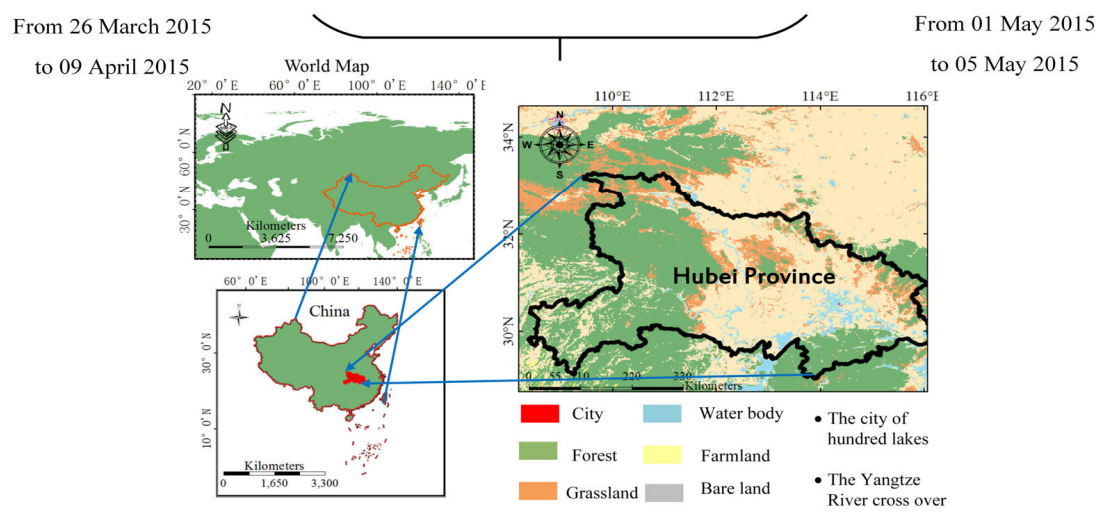

Figure 10. The top figure refers to the Wuhan City. The middle figure refers to the precision measure of Wuhan City and Hubei Province at different times. The bottom figure refers to the Hubei Province. (a) The precision measure of three methods retrieving MODIS products from 26 March 2015 to 9 April 2015 in Wuhan City; (b) The precision measure of three methods retrieving AVHRR and Landsat products from 26 March 2015 to 9 April 2015 in Wuhan City; (c) The precision measure of three methods retrieving MODIS products from 26 March 2015 to 9 April 2015 in Hubei Province; (d) The precision measure of three methods retrieving MODIS products from 01 May 2015 to 5 May 2015 in Hubei Province. 


\subsection{Flood Map Validity}

In this experiment, the proposed APEOPM method achieves higher precision based on semantic enhancement and can be used to obtain multi-scale flood maps based on multi-scale remote sensing images. The APEOPM method presented in Section 2.1 reveals the relationships between product hierarchy and product type. By constructing the instantiation file of the EO data system access protocols and data queries, the proposed method can be used to search for desired EO data products according to the data type in the search results.

Satellite-derived rainfall products are useful for early drought and flood warnings and can be used to overcome the problem of sparse, unevenly-distributed and erratic rain gauge observations when their accuracy is well known [46]. Hence, with additional considerations, flood mapping should be validated based on the actual precipitation situation of the study area, as described by Tan and Yong [47]. In addition, monthly data from NASA's Tropical Rainfall Measuring Mission (TRMM) can be used to calculate precipitation $[48,49]$. The rainfall data are obtained from TRMM rather than from the prototype based on the model proposed in Section 2. In this case, monthly precipitation data between August 2014 and April 2015 were obtained from TRMM 3B43, V6. Wuhan's weather is located in a subtropical monsoon climate with significant precipitation seasonality. Thus, the precipitation at this station during the rainy and winter seasons is different (Figure 11a). The amount of precipitation that occurred during April 2015 was greater than the amount of precipitation that occurred in any other month (Figure 11a). In addition, it is known that an abrupt torrential rainfall event occurred on 31 March 2015 (Figure 11b). Thus, we concluded that the mean NDWI value on the flood map during days with torrential rainfall would be greater than the mean NDWI values of other flood maps based on the NDWI index. Moreover, located in the east of Jianghan plain, Wuhan city covers a plain area of 8467 square kilometers, which can be considered as the a whole river catchment in the hydrological perspective. We can confirm this conclusion by comparing the waterlogging NDWI maps of Wuhan city from different periods.

(a)

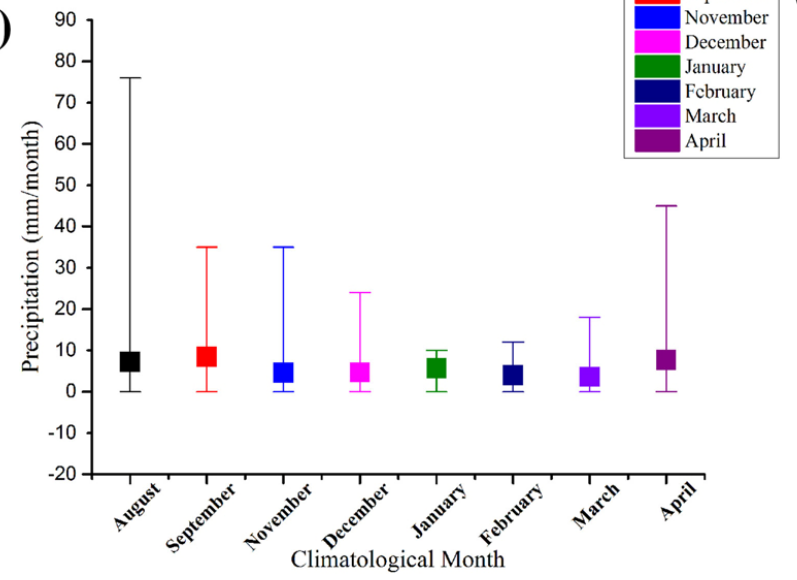

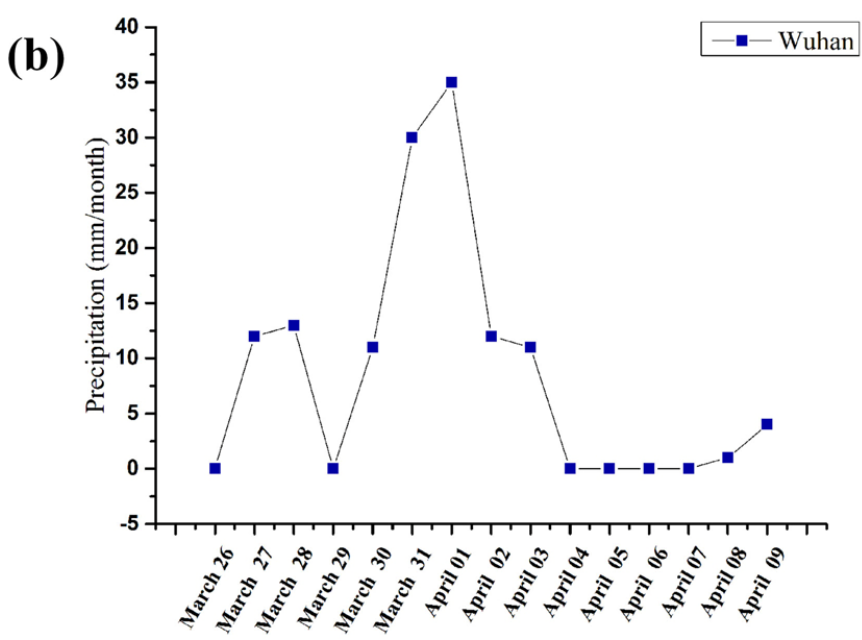

Figure 11. (a) The mean climatological monthly precipitation (TRMM data in $\mathrm{mm} / \mathrm{month}$ ) and standard deviation from August 2014 to April 2015 in Wuhan city; (b) daily precipitation (mm/day) from 26 March 2015 through 9 April 2015 in Wuhan city. 


\section{Discussion}

\subsection{Comparisons with Other Related Methods}

The study proposed a sharable and efficient APEOPM metadata model for constructing an EO data system to retrieve remote sensing data for flood mapping. The experiment was conducted to test the flexibility of the model. Different spatial ranges and different temporal ranges were tested to analyze the precision of the model. However, the comparisons with other related methods in terms of several features are shown in Table 4. The proposed model supports the four features listed in Table 4. However, the CGDC and GEOSS does not support or partially support them.

Table 4. Comparisons with other models.

\begin{tabular}{ccccc}
\hline \multirow{2}{*}{$\begin{array}{c}\text { Models or } \\
\text { Methods }\end{array}$} & $\begin{array}{c}\text { Support Heterogeneous } \\
\text { EO Data System' Access } \\
\text { Protocol Conversion }\end{array}$ & $\begin{array}{c}\text { Support Encoding of Metadata } \\
\text { Archived in the EO Data System }\end{array}$ & $\begin{array}{c}\text { Precision of Data } \\
\text { Retrieval }\end{array}$ & $\begin{array}{c}\text { Strong } \\
\text { Extendibility }\end{array}$ \\
\hline APEOPM & $\bullet$ & $\bullet$ & $85 \% \sim 100 \%$ & $\bullet$ \\
\hline CGDC & $\bullet$ & 0 & $58 \% \sim 85 \%$ & 0 \\
\hline GEOSS & $\bullet$ & 0 & $79 \% \sim 89 \%$ & $\bullet$ \\
\hline & Note: $\bullet$ support; $\bigcirc$ nonsupport or partial support.
\end{tabular}

\subsection{Supporting Data for the All-Stage Multi-Scale Flood Map}

The proposed APEOPM for constructing an EO data SoS is designed to provide general users with a more convenient, effective and prompt method for accessing heterogeneous EO data systems. The model was based on access to data systems for semantic enhancement, protocol conversion and encoding conversion. Due to different access protocols and different archiving metadata models, heterogeneous EO data systems oppose standard and unified access. The novel model presented in this study provides a unified and efficient method for users to access heterogeneous EO data systems. In the model, an APEOPM access metadata model and an enhanced EOP metadata model are used. The APEOPM unifies different protocols of different EO data systems. The enhanced EOP metadata model unifies different archiving metadata models from different EO data systems, which is considered as a seven-tuple information description structure. This study proposes a novel model for integrating access protocols and archiving metadata models of heterogeneous EO data systems to provide users with a unified, convenient and efficient method for accessing heterogeneous EO data systems. The proposed method achieves higher precision by making full use of the inherited semantics of the product.

In conclusion, APEOPM can shelter the heterogeneity of different EO data systems, which can support the necessary data retrieval in different flood map stages. AVHRR, Terra/MODIS and Landsat 8 OLI data retrieved from heterogeneous EO data systems can help achieve multi-scale flood maps during different flood stages. Thus, it was concluded that APEOPM achieves multi-scale flood map data support during all stages. 


\section{Conclusions and Future Work}

This study proposes using a sharable and efficient model to retrieve EO data for multi-scale flood mapping. We studied Wuhan city in China because Wuhan city contains hundreds of lakes. The access protocol model is helpful for unifying the access protocols for heterogeneous EO data systems. The enhanced EOP can be helpful for encoding multiple EO metadata archived in EO data systems. In addition, the precision of EO data retrieval is promoted through semantic enhancement. In the experiment of Wuhan city and Hubei province, the proposed APEOPM has achieved the best precision in the experiment, about $85 \% \sim 100 \%$. Moreover, the APEOPM successfully supports data to provide the all-stage multi-scale flood map in the experiment. Furthermore, multi-scale mapping has been realized to aid flood monitoring and management.

The APEOPM can achieve one-stop flood mapping during different flood management periods. However, additional research is necessary to obtain a more efficient method. Flood disasters are divided into four phases, including mitigation, preparedness, response and recovery [21]. Therefore, higher temporal resolution flood mapping is significant for flood management. However, the temporal resolution of retrieved data is limited by the proposed model. Therefore, the limitations of temporal resolution during data retrieval can be overcome in future studies.

\section{Acknowledgments}

This work was supported by grants from the National Basic Research Program of China (973 Program) (No. 2011CB707101), the National High Technology Research and Development Program of China (863 Program) (No. 2013AA01A608), the National Nature Science Foundation of China (NSFC) Program (Nos. 41171315, 41301441), the Fundamental Research Funds for the Central Universities (No. 2042014kf0200) and the China Postdoctoral Science Foundation funded project (Nos. 2014M562050, 2015T80829).

\section{Author Contributions}

Nengcheng Chen and Lianjie Zhou conceived of and designed the project. Lianjie Zhou and Zeqiang Chen performed the experiments. Lianjie Zhou wrote the paper. Nengcheng Chen, Lianjie Zhou and Zeqiang Chen reviewed and edited the manuscript. All authors read and approved the manuscript.

\section{Conflicts of Interest}

The authors declare no conflict of interest.

\section{References}

1. Jonkman, S.N. Global perspectives on loss of human life caused by floods. Nat. Hazards 2005, 34, $151-175$.

2. Long, N.T.; Trong, B.D. Flood monitoring of Mekong River Delta, Vietnam using ERS SAR data. In Proceedings of the 22nd Asian Conference on Remote Sensing, Singapore, 5-9 November 2001. 
3. Ghoshal, S.; James, L.A.; Singer, M.B.; Aalto, R. Channel and floodplain change analysis over a 100-year period: Lower Yuba River, California. Remote Sens. 2010, 2, 1797-1825.

4. Khan, S.; Hong, Y.; Gourley, J.; Khattak, M.U.; Groeve T.D. Multi-sensor imaging and space-ground cross-validation for 2010 flood along Indus River, Pakistan. Remote Sens. 2014, 6, 2239-2254.

5. Schumann, G.; Hostache, R.; Puech C.; Hoffmann, L. High-resolution 3-D flood information from radar imagery for flood hazard management. IEEE Trans. Geosci. Remote Sens. 2007, 45, $1715-1725$.

6. Ticehurst, C.; Guerschman, J.P.; Chen, Y. The strengths and limitations in using the daily MODIS open water likelihood algorithm for identifying flood events. Remote Sens. 2014, 6, 11791-11809.

7. NASA ECHO data system. National Aeronautics and Space Administration EOS Clearing House (ECHO). Available online: http://earthdata.nasa.gov/echo (accessed on 8 January 2015).

8. NOAA CLASS data system. NOAA Comprehensive Large Array-data Stewardship System. Available online: http://www.class.noaa.gov (accessed on 8 January 2015).

9. USGS Landsat data system. United States Geological Survey Landsat. Available online: http://www.glcf.umiacs.umd.edu/index.shtml (accessed on 8 January 2015).

10. INPE CBERS data system. Instituto Nacional de Pesquisas Espaciais China Brazil Earth Resources Satellite program. Available online: http://www.cbers.inpe.br/ (accessed on 6 January 2015).

11. DeLaurentis, D. Role of humans in complexity of a system of systems. Digit. Hum. Model. Lect. Notes Comput. Sci. 2007, 4561, 363-371.

12. Zyl, T.V.; Simonis I.; McFerren, G. The sensor web: Systems of sensor systems. Int. J. Digit. Earth 2009, 2, 16-30.

13. Maier, M.W. Architecting principles for systems of systems. Syst. Eng. 1988, 1, 267-284.

14. Liu, S. Employing system of systems engineering in China's emergency management. IEEE Syst. J. 2011, 5, 298-308.

15. Mostafavi, A.; Abraham, D.M.; DeLaurentis, D.A.; Sinfield, J. Exploring the dimensions of systems of innovation analysis: A system of systems framework. IEEE Syst. J. 2011, 5, 256-265.

16. Guzinski, R.; Kass, S.; Huber, S.; Bauer-Gottwein, P.; Jensen, I.H.; Naeimi, V.; Doubkova, M.; Walli, A.; Tottrup, C. Enabling the use of earth observation data for integrated water resource management in Africa with the water observation and information system. Remote Sens. 2014, 6, 7819-7839.

17. Global Earth Observation System of Systems (GEOSS). Available online: http://www.geoportal.org/web/guest/geo_home_stp (accessed on 6 January 2015).

18. Copernicus Programme. Available online: http://copernicus.eu/ (accessed on 6 January 2015).

19. Committee on Earth Observation Satellites. CWIC. CEOS WGISS Integrated Catalog website. Available online: http://cwictest.wgiss.ceos.org/testpage.html (accessed on 6 January 2015).

20. CGCD. Chinese geospatial data cloud data system. Available online: http://www.gscloud.cn (accessed on 6 January 2015).

21. Othman, S.H.; Beydoun, G.; Sugumaran, V. Development and validation of a disaster management metamodel. Inf. Process. Manag. 2014, 50, 235-271.

22. Simonovic, S.P. Social criteria for evaluation of flood control measures: Winnipeg case study. Urban Water J. 1999, 1, 167-175. 
23. Gasperi, J.; Houbie, F.; Woolf, A.; Smolders, S. Earth Observation Metadata Profile of Observations \& Measurements, Version 1.0.0; Open Geospatial Consortium: Wayland, MA, USA, 2012.

24. Bröring, A.; Stasch, C.; Echterhoff, J. OGC Sensor Observation Service Interface Standard, Version 2.0; Open Geospatial Consortium: Wayland, MA, USA, 2012.

25. Botts, M. OpenGIS Sensor Model Language (SensorML) Implementation Specification; Open Geospatial Consortium: Wayland, MA, USA, 2007.

26. Bröring, A.; Echterhoff, J.; Jirka, S.; Simonis, I.; Everding, T.; Stasch, C.; Liang, S.; Lemmens, R. New generation sensor web enablement. Sensors 2011, 11, 2652-2699.

27. Henson, C.A.; Pschorr, J.K.; Sheth, A.P.; Thirunarayan, K. SemSOS: Semantic sensor observation service. In Proceedings of the 2009 International Symposium on Collaborative Technologies and Systems, CTS'09, 2009, Baltimore, MD, USA, 18-22 May 2009; pp. 44-53.

28. Cox, S. OGC Implementation Specification 07-022r1: Observations and Measurements-Part 1Observation Schema; Open Geospatial Consortium: Wayland, MA, USA, 2007.

29. Cox, S. OGC Implementation Specification 07-022r3: Observations and Measurements-Part 2Sampling Features; Open Geospatial Consortium: Wayland, MA, USA, 2007.

30. MODIS product classification and hierarchy Introduction. Available online: http://modis.gsfc.nasa.gov/data/dataprod/index.php (accessed on 6 January 2015).

31. Apache Jena API. Available online: http://jena.apache.org/ (accessed on 6 August 2015).

32. Ancillary Description Writer's Guide, Global Change Master Directory. Available online: http://gcmd.nasa.gov/add/ancillaryguide/index.html (accessed on 6 January 2015).

33. Content Standard for Digital Geospatial Metadata: Extensions for Remote Sensing Metadata; Document Number: FGDC-STD-012e2002; Federal Geographic Data Committee: Washington, DC, USA, 2002.

34. ISO 19115: Geographic Information_Metadata; International Organization for Standardization: Geneva, Switzerland, 2003; p. 140.

35. ISO19115-2: Geographic Information_Metadata_Part 2: Extensions for Imagery and Gridded Data; International Organization for Standardization: Geneva, Switzerland, 2007; p. 54.

36. ISO 19130: Geographic Information_Imagery Sensor Models for Geopositioning; International Organization for Standardization: Geneva, Switzerland, 2008; p. 156.

37. GB/Z 24357-2009: Geographic Information Metadata XML Implementation; Chinese Geographic Information Committee: Beijing, China, 2009.

38. Di, L.; Moe, K.; Yu, G.; Metadata requirements analysis for the emerging sensor web. Int. J. Digit. Earth 2009, 2, 3-17.

39. Gamma, E.; Helm, R.; Johnson, R.; Vlissides, J. Design Patterns, 1st ed.; Addison Wesley: Boston, MA, USA, 1995; p. 395.

40. SosSystem prototype. Available online: http://gsw.whu.edu.cn:8080/SosSystem/ (accessed on 22 July 2015)

41. Gao, B.C. NDWI-A normalized difference water index for remote sensing of vegetation liquid water from space. Remote Sens. Environ. 1996, 58, 257-266.

42. McFeeters, S.K. The use of the normalized difference water index (NDWI) in the delineation of open water features. Int. J. Remote Sens. 1996, 17, 1425-1432. 
43. Chen, D.; Jackson, T.J.; Li, F.; Cosh, M.H.; Walthall, C.; Anderson, M. Estimation of vegetation water content for corn and soybeans with a normalized difference water index (NDWI) using Landsat Thematic Mapper data. IEEE Int. Geosci. Remote Sens. Symp. 2003, 4, 2853-2856.

44. Webster T.L. Flood risk mapping using LiDAR for Annapolis Royal, Nova Scotia, Canada. Remote Sens. 2010, 2, 2060-2082.

45. Egghe, L. The measures precision, recall, fallout and miss as a function of the number of retrieved documents and their mutual interrelations. Inf. Process. Manag. 2008, 44, 856-876.

46. Toté, C.; Patricio, D.; Boogaard, H.; Wijngaart, R.V.D.; Tarnavsky, E.; Funk, C. Evaluation of satellite rainfall estimates for drought and flood monitoring in Mozambique. Remote Sens. 2015, 7 , $1758-1776$.

47. Tan, M.L.; Ibrahim, A.L.; Duan, Z.; Cracknell, A.P.; Chaplot, V. Evaluation of six high-resolution satellite and ground-based precipitation products over Malaysia. Remote Sens. 2015, 7, 1504-1528.

48. Yong, B.; Hong, Y.; Ren, L.; Gourley, J.J.; Huffman, G.J.; Chen, X. Assessment of evolving TRMM-based multisatellite real-time precipitation estimation methods and their impacts on hydrologic prediction in a high latitude basin. J. Geophys. Res.: Atmos. 2012, 117, doi:10.1029/2011JD017069.

49. Su, F.; Hong, Y.; Lettenmaier, D.P. Evaluation of TRMM Multisatellite Precipitation Analysis (TMPA) and its utility in hydrologic prediction in the La Plata Basin. J. Hydrometeorol. 2008, 9, 622-640.

(C) 2015 by the authors; licensee MDPI, Basel, Switzerland. This article is an open access article distributed under the terms and conditions of the Creative Commons Attribution license (http://creativecommons.org/licenses/by/4.0/). 